REVIEW

\title{
Yoga for anxiety: a systematic review of the research evidence
}

\author{
G Kirkwood, H Rampes, V Tuffrey, J Richardson, K Pilkington
}

Br J Sports Med 2005;39:884-891. doi: 10.1136/bjsm.2005.018069

Between March and June 2004, a systematic review was carried out of the research evidence on the effectiveness of yoga for the treatment of anxiety and anxiety disorders. Eight studies were reviewed. They reported positive results, although there were many methodological inadequacies. Owing to the diversity of conditions treated and poor quality of most of the studies, it is not possible to say that yoga is effective in treating anxiety or anxiety disorders in general. However, there are encouraging results, particularly with obsessive compulsive disorder. Further well conducted research is necessary which may be most productive if focused on specific anxiety disorders.

See end of article for authors' affiliations

....................

Correspondence to: K Pilkington, Research Council for

Complementary Medicine (RCCM)/University of Westminster, c/o School of Integrated Health, University of Westminster, 115 New Cavendish Street, London WIW 6UW, UK; K.Pilkington@ westminster.ac.uk

Accepted 20 June 2005
A nxiety disorders are among the most prevalent mental health problems found in the community in the United Kingdom according to the survey carried out by the Office for National Statistics (ONS) in the year 2000. ${ }^{1}$ Conditions such as mixed anxiety and depressive disorder, generalised anxiety disorder, phobias, obsessive compulsive disorder, and panic disorder make up over $86 \%$ of neurotic disorders found. Excessive anxiety is a key component or symptom in all of these conditions.

Yoga is defined as a practice consisting of three components: gentle stretching; exercises for breath control; and meditation as a mind-body intervention. ${ }^{2}$ The version used mainly in the West is hatha yoga, which consists of an integration of asana (postures), pranayama (breathing exercise), and meditation. ${ }^{3}$ Although yoga has its origins in Indian culture and religion, it can be practised secularly. ${ }^{2}$ No systematic reviews have been published on the benefits of yoga in anxiety or anxiety disorders. This is despite the fact that a recent analysis of publication trends has shown an increase in publication frequency and growing use of randomised controlled trials to study yoga as a therapeutic intervention. ${ }^{4}$ The only systematic review that looks specifically at yoga as an intervention for any condition is that on yoga in epilepsy, which was inconclusive because of a lack of studies. ${ }^{5}$

The effect of exercise on anxiety has, however, been reviewed. There is some evidence of an anxiolytic effect, ${ }^{6}$ with aerobic exercise possibly more beneficial than non-aerobic exercise. ${ }^{78}$ There is also some evidence that exercise may be particularly beneficial in people with more severe anxiety. ${ }^{79}$ None of these reviews, however, appear to have included yoga as a form of exercise.

There are a number of studies that look at the effects of yoga on anxiety levels in non-clinical samples. Berger and Owen ${ }^{10}$ compared the effects of swimming, fencing, body conditioning, and yoga classes and found that only the yoga treatment group recorded a significant short term reduction in state anxiety. Ray et $a l^{11}$ reported that yoga reduced anxiety but only among male students. Netz and Lidor ${ }^{12}$ showed that participants in yoga as well as swimming and the Feldenkrais method recorded lower anxiety levels than a control group. However, in a study of elderly people, Blumenthal et $a l^{13} 14$ found that yoga participants fared worse than those in an aerobic exercise group and no better than the other treatment regimens on anxiety measures. It is difficult to predict on the basis of the findings of these studies the effect of yoga on people with anxiety or a specific anxiety disorder, and therefore it is important to identify the evidence that is currently available.

\section{METHODS}

\section{Aim and objectives}

The aim of this study was to evaluate the evidence from a range of sources of the effectiveness of yoga for the treatment of anxiety and anxiety disorders.

\section{Summary of the search strategy}

A comprehensive search for clinical research was carried out. Searches were conducted on major biomedical and specialist databases and websites. Citations were sought from relevant reviews and various appropriate specialised books. Relevant websites were also included in the search, including those of specialist yoga and mental health organisations.

\section{Databases}

The following databases were searched between March and June 2004:

- General databases: CINAHL, Cochrane Central Register of Controlled Trials (CENTRAL), Cochrane Database of Systematic Reviews, Database of Abstracts of Reviews of Effects, EMBASE, Medline (and PubMed), PsycINFO

- Specialist CAM databases: AMED, CISCOM

- Specialist yoga websites: International Association of Yoga Therapists, ${ }^{15}$ Yoga Biomedical Trust $^{16}$

- Specialist mental health websites: MIND, ${ }^{17}$ Mental Health Foundation ${ }^{18}$ 
A search of the Cochrane Collaboration Depression, Anxiety and Neurosis (CCDAN) Controlled Trials Register was also conducted in December 2004.

\section{Search terms}

The following terms for yoga and anxiety were used in the search of AMED, CINAHL, EMBASE, Medline and PsycINFO (OVID): (exp yoga OR yoga.mp OR yogic.mp OR asanas.mp OR dhyana.mp OR pranayama.mp OR meditation OR meditat*) AND (exp anxiety OR exp anxiety disorders OR anx\$.mp).

Search strategies were adapted for each of the databases searched. The searches of CISCOM and CCDAN were carried out by the information specialists responsible for these databases. Efforts were made to identify unpublished and ongoing research using relevant databases such as the National Research Register (UK) and Clinicaltrials.gov (US).

\section{Filtering}

This was carried out by two independent researchers, and relevant research was categorised by study type according to a flow chart system developed for this project.

The basic categories used were: randomised controlled trials; controlled clinical trials without randomisation; uncontrolled clinical trials and case series; case reports/ studies; qualitative research; surveys; other research studies.

\section{Selection criteria \\ Types of study}

All clinical trials, controlled and uncontrolled, were identified, but only controlled trials, whether randomised or not, were included in this review. Dissertation abstracts were excluded because of lack of detail of methodology and outcome measures. Attempts were also made to locate relevant qualitative studies.

No language restrictions were imposed at the search and filtering stage.

\section{Types of participants}

All studies were included in which participants were described as suffering from anxiety. This primarily took the form of a diagnosis of an anxiety disorder by whatever diagnostic method was deemed appropriate by the papers' authors. In addition, studies in which participants were suffering from anxiety as determined by the authors via measurement scales and those in which participants were about to undergo a procedure that was anticipated to be anxiety provoking were also included.

\section{Types of intervention}

Yoga of various styles. Studies where the intervention was solely meditation based were not included.

\section{Types of outcome measures}

Anxiety rating scales and scales to measure specific symptoms of anxiety disorders.

\section{Data collection and appraisal}

Data was extracted systematically using a specially designed data extraction form. Data extracted included details of selection criteria and procedure, the participants, the intervention and any comparison or control intervention, aspects of the methodology, and outcome measures and results.

Clinical trials were appraised using a standardised appraisal framework specifically developed for this project and based on criteria recommended by the Centre for Reviews and Dissemination. ${ }^{19}$

Study quality was measured by recording details of method of randomisation, concealment of allocation, blinding of assessors, and loss to follow up. Also recorded were statistical power, presence or absence of intention to treat analysis, reporting of baseline characteristics, and outcome measures reported.

For each study, two researchers conducted data extraction and appraisal independently, and any disagreements or discrepancies were resolved by discussion. Where consensus could not be obtained, a third reviewer was available for consultation.

\section{Data analysis}

The primary outcome measure was taken to be that stated by the study or the first anxiety measure mentioned if none was identified. Additional post hoc (calculated as part of this review) calculations, including the mean difference and standardised mean difference (effect size), were performed where possible to estimate the effect and to allow comparisons to be made between the studies. ${ }^{20}$

\section{Clinical commentaries}

A clinician with relevant training and experience was asked to comment on each study focusing on clinical relevance and practical issues. Commentary frameworks were specifically developed for this project, and these incorporate a number of closed and open questions with space for further comments. Table 1 provides summaries of these commentaries.

\section{RESULTS}

\section{Systematic reviews}

There were no systematic reviews found specifically on the topic of yoga for anxiety or anxiety disorders, although yoga is included in a systematic review of complementary and self help treatment for anxiety disorders. ${ }^{21}$

\section{Randomised and non-randomised controlled trials}

Eight studies were found. All were controlled trials; six were randomised $^{22-27}$ and two were non-randomised. ${ }^{28}{ }^{29}$ In five studies the inclusion criterion was a diagnosis of an anxiety disorder (anxiety neurosis, obsessive compulsive disorder, and psychoneurosis). ${ }^{22-24} 28{ }^{29}$ In two studies participants were suffering from anxiety, namely examination anxiety and snake phobia, as determined by the authors from measurement scales, ${ }^{25}{ }^{27}$ and in the remaining study, participants were about to undergo a procedure, which was anticipated to be anxiety provoking, namely an examination. ${ }^{26}$

\section{Other studies}

No relevant qualitative research studies were located.

\section{Excluded studies}

Four studies (five papers) were excluded in which the participants were ostensibly healthy, and anxiety was measured as one of a battery of outcome measures. ${ }^{10-14} \mathrm{~A}$ brief description of these has already been given in the introduction. Four studies in which the primary inclusion criterion was a physical illness were excluded. ${ }^{30-33}$ Two studies were excluded because of the lack of a control group. ${ }^{34}$

\section{Language of studies included}

All studies were in English, six were from India and one each from the United States and Canada.

\section{Summary of each study}

Table 1 presents a breakdown of the study methodology plus the main results as identified in the original study plus post hoc calculations.

In a hospital based study in the United States, ShannahoffKhalsa et $a l^{22}$ used yoga as a treatment intervention for obsessive compulsive disorder (OCD). Study participants 


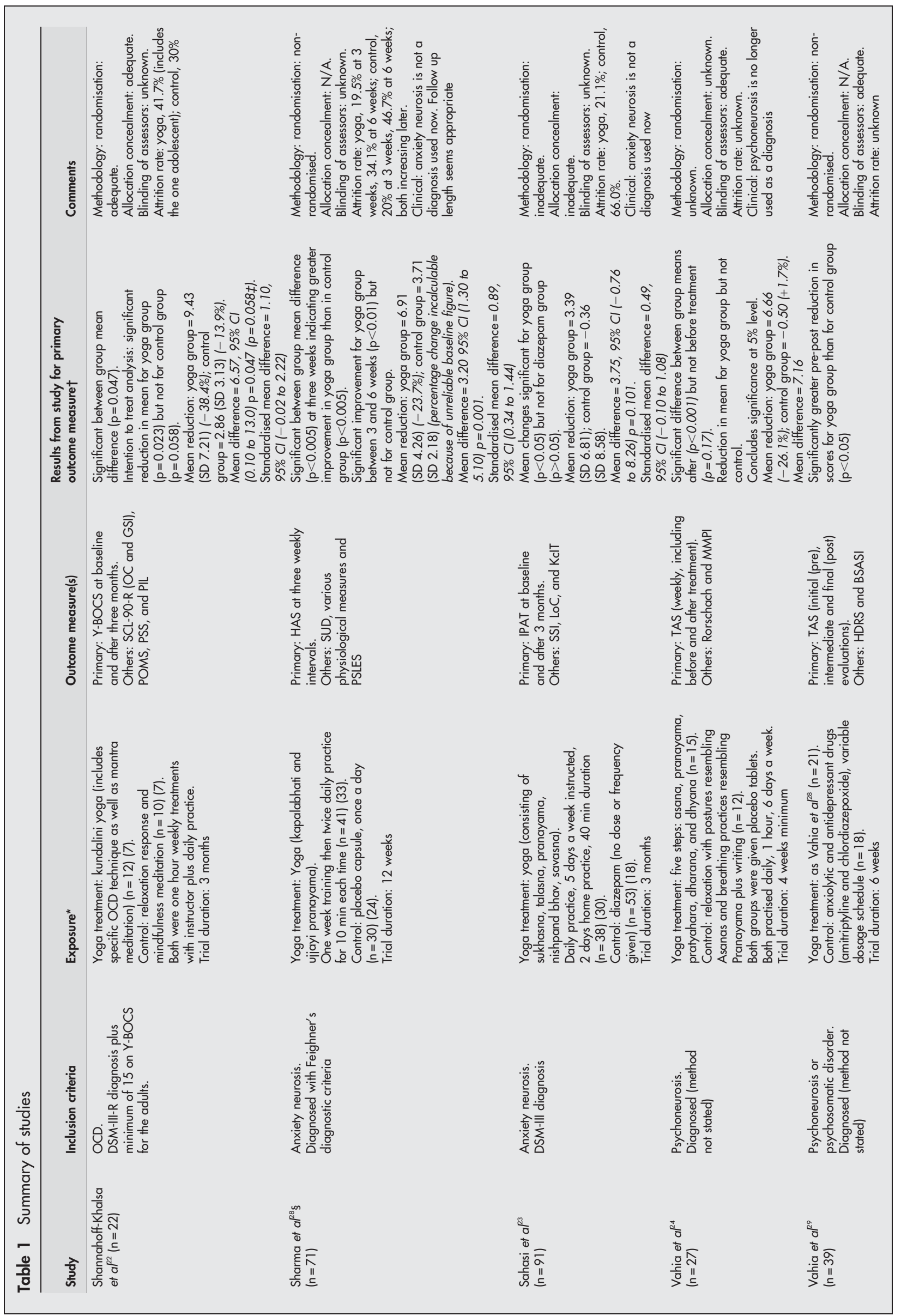




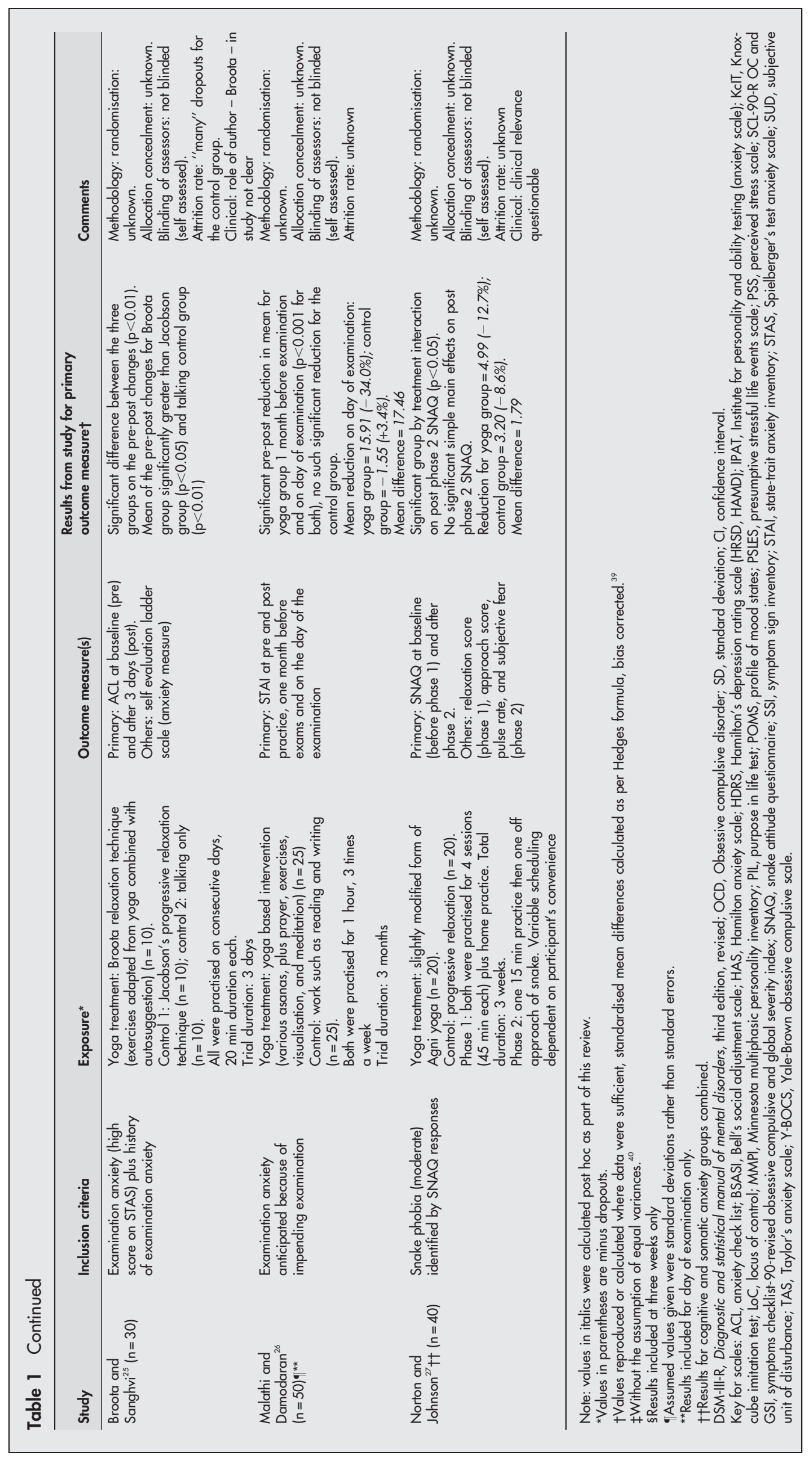


were all from the community, each with a confirmed DSMIII-R (Diagnostic and statistical manual of mental disorders, third edition, revised) diagnosis of OCD. The sample was randomised, with 12 practising a version of kundalini yoga, which consisted of a number of techniques including mantra meditation as well as an OCD specific technique, which involved breathing through only the left nostril (see Shannahoff-Khalsa $e t a l^{36}$ for full details). The remaining 10 patients practised a control regimen, which was also meditative, enabling the researchers to test the hypothesis that "meditation techniques in general may not be effective" and that "disorder-specific" techniques may be required. At three months, the yoga group showed significantly greater improvements on the Yale-Brown obsessive compulsive scale and other scales than the control group. Post hoc analysis indicates, however, that this may only be true under the assumption of equal variances (table 1). A reduction of 20$35 \%$ on the Yale-Brown obsessive compulsive scale is deemed clinically significant by the authors. This was achieved for the yoga group (38.4\% reduction) but not the control group ( $13.9 \%$ reduction).

Two hospital based Indian studies investigated yoga as a treatment for anxiety neurosis among psychiatric outpatients diagnosed by either Feighner's diagnostic criteria ${ }^{28}$ or DSMIII. ${ }^{23}$ In a non-randomised study, Sharma et al ${ }^{28}$ found significantly greater improvement in the yoga group than the placebo control group on the Hamilton anxiety scale measures, at least in the first three weeks of the trial. After three weeks there was a reduction of $23.7 \%$ among the yoga group. This reduction is likely to be of clinical significance; however, the mean Hamilton anxiety scale score of 22.7 after the intervention is still at a level that would normally require treatment. ${ }^{37}$ Other results based on the subjective intensity of anxiety symptoms were more mixed. Sahasi et $a l^{23}$ compared yoga with diazepam, an established anxiolytic, in a randomised controlled trial. At the end of the three month trial, the authors discovered that the yoga group had recorded significantly lower Institute for Personality and Ability Testing anxiety scale scores and symptom sign inventory scores, findings that were not replicated in the diazepam group. They also found that overall improvement as assessed by the consultant psychiatrist was greater for the yoga group (76.7\%) than for the diazepam group $(50 \%)$, although no statistical significance is attached to this. A post hoc $t$ test on the between group mean difference for the Institute for Personality and Ability Testing score was non-significant (table 1).

Vahia et al ${ }^{24}{ }^{29}$ conducted two studies as part of a larger nine year trial of what they term psychophysiological treatment for psychoneurosis. Psychoneurosis is a term no longer used as a diagnosis, which originally referred to both anxiety and depressive disorders. The psychophysiological treatment was a form of yoga based on the concepts of Patanjali. In the first of the studies, ${ }^{24}$ the yoga treatment was compared with a pseudo-yoga treatment, designed to act as a control which could ensure patient blinding. Both groups of participants were equivalent for baseline anxiety measured by Taylor's anxiety scale. After their respective treatments, the genuine yoga group recorded significantly lower anxiety scores than the control group. In the second study, ${ }^{29}$ yoga treatment was compared with the anxiolytic and antidepressant drugs chlordiazepoxide and amitriptyline, this time among patients with a diagnosis of either psychoneurosis or psychosomatic disorder. The results suggested that the patients who had practised yoga recorded a significantly greater reduction in Taylor's anxiety scale score than those in the drug group.

Two Indian studies investigated the use of yoga as a treatment for examination anxiety. ${ }^{25}{ }^{26}$ Broota and Sanghvi ${ }^{25}$ carried out a three way comparison between their Broota relaxation technique, Jacobson's progressive relaxation technique, and a control among university students who had a history of examination anxiety and recorded a high baseline score on Spielberger's test anxiety scale. The Broota relaxation technique consists of a set of four exercises adapted from yoga, combined with auto-suggestion. After the three day intervention, the Broota relaxation group recorded a significantly greater improvement on the anxiety check list measure than the Jacobson's progressive relaxation group and the control group. There were no significant between group differences for the self evaluation ladder scale measure. In a three month trial conducted with medical students, Malathi and Damodaran ${ }^{26}$ found a significant reduction in anxiety after treatment for the yoga group one month before examinations and on the actual day of examinations. There was no such significant reduction for the control group. Post hoc $t$ tests between the group means after treatment showed a significant difference one month before the examination and on the day of the examination $(\mathrm{p}<0.001$ for both). No such difference existed before treatment at either time point. On the day of the examination, the mean state-trait anxiety inventory score for the yoga group fell by $34.0 \%$ from the moderate anxiety range before treatment to the low anxiety range after treatment, representing a clinically significant change. ${ }^{38}$

Finally, in a study of the management of specific phobias, Norton and Johnson ${ }^{27}$ treated snake anxious, first year psychology students with either yoga or progressive relaxation. The aim of the study was to test the hypothesis that yoga may be more appropriate for cognitive anxiety whereas progressive relaxation may be more beneficial for somatic anxiety. The results give some support for this hypothesis.

Out of the eight studies described above, standardised mean differences were calculated for only three studies where there were sufficient data and are presented in table 1.

\section{Appraisal of the methodology Measure of study quality}

The reporting of study methodology was poor in most of the studies, and there were also some methodological inadequacies (table 1). The potential for bias is therefore high. Although six out of eight studies were randomised, only one showed an adequate method of randomisation and allocation concealment. ${ }^{22}$ One study used an inadequate serial numbering method with a subsequent block move of patients to the control group because of an inability to perform yoga. ${ }^{23}$ In all the other randomised controlled trials, no detail of the method of randomisation or concealment of allocation is given. Given the nature of yoga, blinding of participants would generally not be considered feasible. Two studies were described as double blind, ${ }^{24}{ }^{29}$ although participants were not blinded in one of the studies. ${ }^{29}$ It is still possible to blind the outcome assessor, and this was carried out in both of these studies, ${ }^{24}{ }^{29}$ but was either not done, was not possible because of self assessment, or is not mentioned in the others. There was a large loss to follow up in the studies by Sahasi $e t a^{23}$ and Sharma et $a^{28}$ (beyond three weeks), and this was a concern in the paper of Shannahoff-Khalsa et al, ${ }^{22}$ which may bias the results. None of these three studies gave any reasons for the dropouts, and no detail at all was given in the others.

\section{Other methodology}

Only one study reported a power calculation, fulfilled the minimum sample size even allowing for dropouts, and gave information on the clinical significance of the results. ${ }^{22}$ The issue of clinical significance has been addressed in this review where possible, but two of the studies lacked sufficient data, ${ }^{23} 29$ two studies used their own scales, ${ }^{25} 27$ and the 
necessary information on the scale used in one was not available. ${ }^{24}$ In only one of the studies was any intention to treat analysis carried out and reported. ${ }^{22}$ Two of the studies clearly did not calculate their results on this basis, ${ }^{23}{ }^{28}$ and in the others there was no mention of this issue or there was insufficient detail to deduce the basis of the calculations. The reporting of age, sex, and baseline anxiety distribution between the groups was inadequate in some studies. ${ }^{23-29}$ This is a particularly serious problem in the study by Sahasi et $a^{2^{23}}$ because of the block move of participants after randomisation. Three studies detailed age and sex distribution. ${ }^{22}{ }^{23}$ Baseline anxiety figures for the primary outcome measure were satisfactorily equivalent between the treatment groups in three studies, ${ }^{22} 2426$ and in one study equivalence is stated. ${ }^{27}$ The main co-interventions dealt with were concurrent drug treatments and psychotherapy. Three of the studies gave some detail on this issue, but none of them dealt with it in any way adequately or checked that any instructions given were adhered to. ${ }^{22} 2328$ The other studies gave no detail on this issue. Feighner's diagnostic criteria, a forerunner to the inclusion of diagnostic criteria in the DSM, was used in one study. ${ }^{28}$ Two studies did not state which diagnostic criteria they used..$^{24}{ }^{29}$ Two of the studies had errors in the labelling in the tables, which necessitated some assumptions in the interpretation of the data in them..$^{26}{ }^{27}$ In one study, some of the data reproduced in the tables were unreliable. ${ }^{28}$

\section{Statistical methods}

Adequate statistical methods were used in most studies. ${ }^{22}{ }^{25}$ 27-29 In one study where only a pre-post $t$ test for each group was performed, there were sufficient data to allow a post hoc, between group comparison on the mean difference to be performed. ${ }^{23}$ The remaining two studies had only sufficient data to allow a $t$ test on the post-test means, although baseline equivalence with respect to anxiety measure ensured that this comparison was meaningful. ${ }^{24} 26$

\section{DISCUSSION}

A number of controlled trials, both randomised and nonrandomised, that tested yoga as an intervention with respect to anxiety and anxiety disorders are described in this review. There were eight studies in which participants were suffering from anxiety or had a diagnosed anxiety disorder, and all registered positive results in favour of yoga. However, the overall reporting of study methodology was poor, and there were many methodological inadequacies in the studies. It is encouraging though that the best study methodologically ${ }^{22}$ provided a positive result.

The smallest standardised mean difference was in the study by Sahasi et al, ${ }^{23}$ which is perhaps not surprising given the choice of diazepam as a control treatment. The other two studies that had sufficient data to allow standardised mean differences to be calculated produced respectable figures demonstrating a notable effect. ${ }^{22} 28$

\section{What is already known on this topic}

- A systematic review of complementary and self help treatments for anxiety disorders concluded that, in the absence of well conducted studies, it is impossible to say whether yoga is effective

- There is surprisingly little research on yoga for clinical anxiety
There is a shortage of information on safety or contraindications with respect to yoga for psychiatric disorders. Little additional information on adverse effects related to the practice of yoga can be gained from the studies included in this review. Shannahoff-Khalsa et al ${ }^{22}$ reported an absence of adverse effects, but there is no mention of adverse effects within the other studies. As well as recommending that medical advice be sought before yoga is taken up by anybody with a medical condition, Ernst ${ }^{2}$ states that certain postures are not recommended during pregnancy, that overstretching joints may lead to physical damage, and that the meditation aspect may best be avoided by anyone with a history of psychotic or personality disorder. Becker ${ }^{41}$ states that meditation is impossible in the presence of active psychosis. No further details or references are given in either source. The evidence in general on contraindications with regard to psychosis and possible psychotic side effects of meditation appears at this stage to be in the form of case reports, ${ }^{42}{ }^{43}$ and is certainly an area that requires more investigation. With exercise in general, there is some concern that undertaking a programme that is too intense for a person can lead to a worsening of mood. ${ }^{7}$

Motivation and compliance may also be issues that require consideration before recommendation of a programme such as yoga. ${ }^{41}$ Low participation and high attrition rates, 50\% lost within three to six months, have been found for exercise. ${ }^{7}$ Dropout rates were significant or high in all three studies that reported on this. ${ }^{22}{ }^{23}{ }^{28}$ The ability to pursue a commitment to a yoga programme may well be an issue for clients with anxiety disorders, as may the type of yoga used. There are many different forms of yoga, ${ }^{44}$ and some may be more suitable than others. Careful consideration should be given to these matters before recommendation of any programme, and it would be desirable for instructors to have suitable mental health experience. Nespoor ${ }^{45}$ provides some useful tips on compliance, such as using family support structures and emphasising the non-competitive nature of yoga.

The issue of publication bias has not been dealt with, although efforts were made to find unpublished studies and ongoing research. It is possible, however, that other, less positive findings remain unreported. A meta-analysis of the results was not considered appropriate because of insufficient data and study heterogeneity, mainly in the conditions treated.

If yoga does produce an anxiolytic effect, the exact causal mechanism is likely to be complex. Yoga may best be delivered as a complete intervention, and if different aspects are delivered separately, such a reductionist approach may result in loss of efficacy or effectiveness. Having said that, it is still worth while devising appropriate controls in an attempt to tease out the yoga specific effects. Similar to exercise, biochemical or physiological mechanisms as well as improvements in self esteem and social situation may

\section{What this study adds}

- This new review concentrates exclusively on yoga and is broader in its remit in that it addresses anxiety and anxiety disorders

- Owing to the diversity of conditions treated and the poor quality of most of the studies, it is still not possible to say that yoga is effective in treating anxiety or anxiety disorders in general, but there are encouraging results, particularly with obsessive compulsive disorder 
well be important, ${ }^{46}$ as could distraction from negative thoughts.

Yoga is an attractive therapeutic option because of its popularity recently demonstrated in the United States ${ }^{47}$ and, like exercise, may be of particular use where clients reject ostensibly psychological diagnoses and treatments. ${ }^{7}$ The National Institute for Clinical Excellence (NICE) recommend that patients with panic disorder and generalised anxiety disorder are informed about exercise as part of good general health. ${ }^{48}$ If proved efficacious, yoga would be an attractive option because it is non-pharmacological, has minimal adverse effects if practised as recommended, and enjoys international acceptance. ${ }^{5}$

In summary, the eight studies reviewed here report positive findings for the use of yoga in $\mathrm{OCD}^{22}$ examination anxiety, ${ }^{25}{ }^{26}$ snake phobia, ${ }^{27}$ anxiety neurosis, ${ }^{23}{ }^{28}$ and psychoneurosis, ${ }^{24} 29$ although the latter two diagnostic terms are no longer used. There were, however, many methodological inadequacies, and only the OCD study ${ }^{22}$ could be described as being methodologically rigorous.

Owing to the diversity of conditions treated and the poor quality of most of the studies, it is not possible to say that yoga is effective in treating anxiety or anxiety disorders in general. However, there are encouraging results, particularly with OCD. Further well conducted research is necessary which may be most productive if focused on specific anxiety disorders.

\section{ACKNOWLEDGEMENTS}

We thank the following: Anelia Boshnakova, Electronic Information Officer, RCCM for advice and support with search strategies and searches; Hugh McGuire, Trial Search Coordinator, Institute of Psychiatry, London for searches of the CCDAN database; Dr Ursula Werneke, Consultant Psychiatrist, Homerton Hospital, London for helpful comments on the draft review; The Project Advisory Group and Specialist Advisory Group (mental health) for the NHS Priorities Project for advice and support to the project.

\section{Authors' affiliations}

G Kirkwood, Research Council for Complementary Medicine, London, UK

H Rampes, Barnet, Enfield \& Haringey Mental Health NHS Trust, Northwest Community Mental Health Team, Edgware, Middlesex, UK V Tuffrey, School of Integrated Health, University of Westminster, London, UK

J Richardson, Faculty of Health and Social Work, University of Plymouth, Plymouth, UK

K Pilkington, Research Council for Complementary Medicine, London, UK. School of Integrated Health, University of Westminster, London, UK

The NHS Priorities Project is funded by the Department of Health. The views and opinions expressed are those of the authors and do not necessarily reflect those of the Department of Health.

Competing interests: none declared

\section{REFERENCES}

Office for National Statistics. Psychiatric morbidity among adults living in private households. London: The Stationery Office, 2000.

2 Ernst E. Therapies: yoga (section 3). In: Ernst E, ed. The desktop guide to complementary and alternative medicine. An evidence-based approach. Edinburgh: Mosby, 2001:76-8.

3 Riley D. Hatha yoga and the treatment of illness. Altern Ther Health Med 2004; 10:20-1.

4 Khalsa SBS. Yoga as a therapeutic intervention: a bibliometric analysis of published research studies. Indian J Physiol Pharmacol 2004;48:269-85.

5 Ramaratnam S, Sridharan K. Yoga for epilepsy (Cochrane Review). Cochrane Library. Issue 3. Chichester: John Wiley \& Sons, Ltd, 2004.

6 Petruzzello S, Landers D, Hatfield B, et al. A meta-analysis on the anxietyreducing effects of acute and chronic exercise: outcomes and mechanisms. Sports Med 1991;11:143-82.

7 Salmon P. Effects of physical exercise on anxiety, depression, and sensitivity to stress: a unifying theory. Clin Psychol Rev 2001;21:33-61.

8 Scully D, Kremer J, Meade M, et al. Physical exercise and psychological well being: a critical review. Br J Sports Med 1998;32:111-20.
9 Dunn AL, Trivedi MH, O'Neal HA. Physical activity dose-response effects on outcomes of depression and anxiety. Med Sci Sports Exerc 2001;33:S587-97.

10 Berger BG, Owen DR. Stress reduction and mood enhancement in four exercise modes: swimming, body conditioning, hatha yoga, and fencing Res Q Exerc Sport 1988;59:148-59.

11 Ray US, Mukhopadhyaya S, Purkayastha SS, et al. Effect of yogic exercises on physical and mental health of young fellowship course trainees. Indian J Physiol Pharmacol $2001 ; 45: 37-53$.

12 Netz Y, Lidor R. Mood alterations in mindful versus aerobic exercise modes. J Psychol 2003; 137:405-19.

13 Blumenthal JA, Emery CF, Madden DJ, et al. Cardiovascular and behavioural effects of aerobic exercise training in healthy older men and women. J Gerontol 1989:44:M147-57.

14 Blumenthal JA, Emery CF, Madden DJ, et al. Long-term effects of exercise on psychological functioning in older men and women. $J$ Gerontol 1991;46:352-61.

15 International Association of Yoga Therapists. http://iayt.org/ (accessed 10 Nov 2004)

16 Yoga Biomedical Trust. http://www.yogatherapy.org/ laccessed 10 Nov 2004).

17 MIND. http://www.mind.org.uk/ (accessed 10 Nov 2004).

18 Mental Health Foundation. http://www.mentalhealth.org.uk/ laccessed 10 Nov 2004)

19 Centre for Reviews, Dissemination (CRD). Report number 4 (2nd ed). Undertaking systematic reviews of research on effectiveness. York: CRD, 2001.

20 The Cochrane Collaboration. Cochrane reviewers' handbook 4.2.2. Updated March, 2004:78-9.

21 Jorm AF, Christensen H, Griffiths KM, et al. Effectiveness of complementary and self-help treatments for anxiety disorders. Med J Aust 2004;181:S29-46.

22 Shannahoff-Khalsa DS, Ray LE, Levine S, et al. Randomized controlled trial of yogic meditation techniques for patients with obsessive-compulsive disorder. CNS Spectr 1999:4:34-47.

23 Sahasi G, Mohan D, Kacker C. Effectiveness of yogic techniques in the management of anxiety. Journal of Personality Clinical Studies 1989;5:51-5.

24 Vahia NS, Doongaii DR, Jeste DV, et al. Further experience with the therapy based upon concepts of Patanjali in the treatment of psychiatric disorders. Indian J Psychiatry 1973;15:32-7.

25 Broota A, Sanghvi C. Efficacy of two relaxation techniques in examination anxiety. Journal of Personality Clinical Studies 1994;10:29-35.

26 Malathi A, Damodaran A. Stress due to exams in medical students: role of yoga. Indian J Physiol Pharmacol 1999;43:218-24.

27 Norton GR, Johnson WE. A comparison of two relaxation procedures for reducing cognitive and somatic anxiety. J Behav Ther Exp Psychiatry 1983; 14:209-14

28 Sharma I, Azmi SA, Settiwar RM. Evaluation of the effect of pranayama in anxiety state. Alternative Medicine 1991;3:227-35.

29 Vahia NS, Doongaji DR, Jeste DV, et al. Psychophysiologic therapy based on the concepts of Patanjali. A new approach to the treatment of neurotic and psychosomatic disorders. Am J Psychother 1973;27:557-65.

30 Broota A, Varma R, Singh A. Role of relaxation in hypertension. Journal of Indian Academy of Applied Psychology 1995;21:29-36.

31 Cohen L, Warneke C, Fouladi RT, et al. Psychological adjustment and sleep quality in a randomized trial of the effects of a Tibetan yoga intervention in patients with lymphoma. Cancer 2004; 100:2253-60.

32 Oken BS, Kishiyama S, Zajdel D, et al. Randomized controlled trial of yoga and exercise in multiple sclerosis. Neurology 2004;62:2058-64.

33 Taneja I, Deepak KK, Poojary G, et al. Yogic versus conventional treatment in diarrhea-predominant irritable bowel syndrome: a randomized control study. Appl Psychophysiol Biofeedback 2004;29:19-33.

34 Allen KS, Steinkohl RP. Yoga in a geriatric mental clinic. Activities, Adaptation \& Aging 1987;9:61-8.

35 Bhushan S, Sinha P. Yoganidra and management of anxiety and hostility. Journal of Indian Psychology 2001;19:44-49.

36 Shannahoff-Khalsa D-S. Kundalini yoga meditation techniques for the treatment of obsessive-compulsive and $O C$ spectrum disorders. Brief Treatment Crisis Intervention 2003;3:369-82.

37 Best Treatments - NHS Direct. http://www. besttreatments.co.uk/btuk/ conditions/9962.html (accessed 13 June 2005)

38 Sesti A-M. State Trait Anxiety Inventory (STAI) in medication clinical trials. QoL Newsletter 2000;25:15-16.

39 Curriculum Evaluation and Management Centre. http:// www.cemcentre.org/ebeuk/research/effectsize/Calculator.htm/ laccessed 11 Apr 2004)

40 Woodward M. Epidemiology: study design and data analysis. London: Chapman \& Hall, 1999:77.

41 Becker I. Uses of yoga in psychiatry and medicine (chapter 3). In: Muskin P, ed. Complementary and alternative medicine and psychiatry (Review of psychiatry series, vol 19, no 1; Oldham JM, Riba MB, series eds). Washington, DC: American Psychiatric Press, 2000:111, 133

42 Hansen W. Psychoses and meditation. Ugeskr Laeger 1981;143:20-2.

43 Lazarus AA. Psychiatric problems precipitated by transcendental meditation. Psychol Rep 1976;39:601-2.

44 Hoare S. How do I choose between the different types of yoga? The Mind guide to yoga. Rev, ed. London: MIND, 2004:6-7.

45 Nespoor K. Twelve years of experience with yoga in psychiatry. Int J Psychosom 1993;40:105-7.

46 Fox K. The influence of physical activity on mental well-being. Public Health Nutr 1999;2:411-18. 
47 Saper HB, Eisenberg DM, Davis RB, et al. Prevalence and patterns of adult yoga use in the United States: results of a national survey. Altern Ther Health Med 2004:44-9.

48 National Institute for Clinical Excellence. Anxiety: management of anxiety (panic disorder, with or without agoraphobia, and generalised anxiety disorder) in adults in primary, secondary and community care: quick reference guide. December 2004.

\section{COMMENTARY}

This review is timely, addressing the important question of whether anxiety can be treated by non-pharmacological methods such as yoga, thus avoiding the adverse effects and possible habituation associated with anxiolytics. It highlights the weak methods used in studies of non-pharmacological interventions and the difficulty in performing a meta-analysis of psychological outcome measures. The results are likely to be confounded by lack of blinding, various types of intervention, varying duration of follow ups, and varied outcome measures, making it difficult to present summary outcome data. The need for good quality studies is emphasised.

S Ramaratnam Department of Neurology, Apollo Hospitals, Madras, India; rsridharan@vsnl.com

\section{Clinical Evidence-Call for contributors}

Clinical Evidence is a regularly updated evidence-based journal available worldwide both as a paper version and on the internet. Clinical Evidence needs to recruit a number of new contributors. Contributors are healthcare professionals or epidemiologists with experience in evidence-based medicine and the ability to write in a concise and structured way.

Areas for which we are currently seeking contributors:

- Pregnancy and childbirth

- Endocrine disorders

- Palliative care

- Tropical diseases

We are also looking for contributors for existing topics. For full details on what these topics are please visit www.clinicalevidence.com/ceweb/contribute/index.jsp

However, we are always looking for others, so do not let this list discourage you.

Being a contributor involves:

- Selecting from a validated, screened search (performed by in-house Information Specialists) epidemiologically sound studies for inclusion.

- Documenting your decisions about which studies to include on an inclusion and exclusion form, which we keep on file.

- Writing the text to a highly structured template (about 1500-3000 words), using evidence from the final studies chosen, within 8-10 weeks of receiving the literature search.

- Working with Clinical Evidence editors to ensure that the final text meets epidemiological and style standards.

- Updating the text every 12 months using any new, sound evidence that becomes available. The Clinical Evidence in-house team will conduct the searches for contributors; your task is simply to filter out high quality studies and incorporate them in the existing text.

If you would like to become a contributor for Clinical Evidence or require more information about what this involves please send your contact details and a copy of your CV, clearly stating the clinical area you are interested in, to CECommissioning@bmigroup.com.

\section{Call for peer reviewers}

Clinical Evidence also needs to recruit a number of new peer reviewers specifically with an interest in the clinical areas stated above, and also others related to general practice. Peer reviewers are healthcare professionals or epidemiologists with experience in evidence-based medicine. As a peer reviewer you would be asked for your views on the clinical relevance, validity, and accessibility of specific topics within the journal, and their usefulness to the intended audience (international generalists and healthcare professionals, possibly with limited statistical knowledge). Topics are usually 1500-3000 words in length and we would ask you to review between 2-5 topics per year. The peer review process takes place throughout the year, and out turnaround time for each review is ideally 10-14 days.

If you are interested in becoming a peer reviewer for Clinical Evidence, please complete the peer review questionnaire at www.clinicalevidence.com/ceweb/contribute/peerreviewer.jsp 